\title{
Diálogos na Extensão Universitária sobre a transversalidade de gênero nas Políticas Sociais
}

\author{
Isabelly Andrade de Oliveira ${ }^{1}$, Tatiane de Oliveira Pinto ${ }^{2}$
}

\begin{abstract}
Resumo: No presente artigo são apresentados resultados do projeto de extensão em Direitos Humanos nomeado "Implementação da transversalidade de gênero nas Políticas Sociais: Compreensão e diálogos por meio da extensão universitária. As atividades foram desenvolvidas no período de setembro de 2020 a agosto de 2021, de maneira remota, em função da pandemia do novo Coronavírus, que alterou essas as dinâmicas educacionais e modificou o espaço de diálogo para a possibilidade de uso da internet e das mídias digitais. Nas ações descritas no artigo, procurou-se discutir a perspectiva dos Direitos Humanos e a transversalidade de gênero, dois conceitos que precisam ser ampliados e desmitificados no imaginário social. Os temas abordados pelo projeto não se esgotam com as ações realizadas de maneira on-line/digital, considerando que ainda é preciso bastante articulação e discussão acerca de gênero e as demais categorias que o circundam.
\end{abstract}

Palavras-chave: Gênero. Transversalidade de gênero. Políticas Sociais. Direitos Humanos. Extensão.

Área Temática: Políticas Públicas. Gênero. Direitos Humanos.

\section{Dialogs in the University Extension on the transversality of gender in Social Policies}

\begin{abstract}
This article presents the results of the extension project in Human Rights named "Implementation of gender mainstreaming in Social Policies: Understanding and dialogue through university extension. The activities were carried out from September 2020 to August 2021, remotely, due to the new Coronavirus pandemic, which changed these educational dynamics and modified the space for dialogue for the possibility of using the internet and digital media. In the actions described in the article, an attempt was made to discuss the perspective of Human Rights and the transversality of gender, two concepts that need to be expanded and demystified in the social imagination. The themes covered by the project are not exhausted with the actions carried out online/digitally, considering that it still needs a lot of articulation and discussion about gender and the other categories that surround it.
\end{abstract}

Keywords: Gender. Transversality. Social Policies. Right Humans. Extension.

\section{Diálogos en Extensión Universitaria sobre la transversalidad de género en las Políticas Sociales}

Resumen: Este artículo presenta los resultados del proyecto de extensión en Derechos Humanos denominado "Implementación de la transversalidad de género en las Políticas Sociales: Comprensión y diálogo a través de la extensión universitaria. Las actividades se realizaron desde septiembre de 2020 hasta agosto de 2021, de forma remota, debido a la nueva pandemia de Coronavirus, que cambió estas dinámicas educativas y modificó el espacio de diálogo para la posibilidad de utilizar internet y los medios digitales. En las acciones descritas en el artículo se intentó discutir la perspectiva de los Derechos

${ }^{1}$ Discente do curso de graduação em Serviço Social da Universidade Federal Rural do Rio de Janeiro. Bolsista de Extensão do Programa em Direitos Humanos 2020 - PROEXT/ UFRRJ. Endereço: BR-465, Km 7, Seropédica-Rio de Janeiro. CEP: 23.897-000. Telefone: 24 99908-2926. E-mail: isabelly.andrade20@ hotmail.com

${ }^{2}$ Doutora em História Política e Bens Culturais pelo CPDOC - FGV. Professora do Instituto de Ciências Sociais Aplicadas da Universidade Federal Rural do Rio de Janeiro. Endereço: BR-465, Km 7, Seropédica-Rio de Janeiro. CEP: 23.897-000. Telefone: 21 97668-3252. E-mail: oliveira.tatianede@gmail.com 
Humanos y la transversalidad de género, dos conceptos que necesitan ser ampliados y desmitificados en el imaginario social. Los temas tratados por el proyecto no se agotan con las acciones realizadas online / digitalmente, considerando que aún necesita mucha articulación y discusión sobre género y las demás categorías que lo rodean.

Palabras clave: Género. Politicas Sociales. Derechos Humanos. Extensión.

\section{INTRODUÇÃO}

O presente artigo apresenta resultados obtidos no projeto de extensão em Direitos Humanos, denominado "Implementação da transversalidade de gênero nas Políticas Sociais: Compreensão e diálogos por meio da extensão universitária”, que foi executado por meio de edital da Pró-Reitoria de Extensão da Universidade Federal Rural do Rio de Janeiro (UFRRJ). As atividades foram desenvolvidas no período de setembro de 2020 a agosto de 2021 .

Em termos iniciais, destaca-se o conceito de transversalidade de gênero, situando-o como ponto central das ações governamentais e apreendendo as dinâmicas entre homens e mulheres com o recorte de classe, raça, sexualidade e geração, com a finalidade de reduzir as desigualdades sociais, econômicas e políticas entre o feminino e masculino (ANDRADE; MEYER, BARZOTTO, 2019) ${ }^{\text {i. }}$

O referido conceito foi instituído a partir da IV Conferência Mundial de Mulheres, realizada em Pequim na década de 1990. No Brasil foi reconhecido como um importante fundamento na atuação da Secretaria de Políticas para Mulheres. Segundo Silva et al. (2015), as áreas específicas de trabalho e renda, educação, saúde e enfrentamento à violência podem servir de exemplos e possibilidades de políticas sociais, onde a transversalidade de gênero é fundamental para que se possa promover o acesso das mulheres aos seus direitos e também diminuir as desigualdades entre os gêneros.

Pensar a transversalidade de gênero, no âmbito das políticas sociais, se torna ainda mais urgente no período pandêmico devido às consequências específicas para as mulheres, como os dados de pesquisas atuais têm demonstrado. De acordo com pesquisa realizada pelo IBGE (2018), esse grupo está situado em cargos informais e precários. Além disso, o isolamento social tornou-se uma ameaça para a vida da mulher, considerando as denúncias do disque 180 que aumentaram em 34\% em comparação ao ano de 2019, segundo o Ministério da Mulher, da Família e Direitos Humanos (2020). Nesses termos, são as mulheres os indivíduos mais prejudicados, social e economicamente, no contexto da pandemia.

Em termos gerais, as ações de extensão possuem o compromisso de democratizar o conhecimento produzido na universidade à comunidade externa e, no caso do projeto em tela, em virtude do isolamento social demandado pela pandemia da COVID-19, esse processo de transferência de conhecimentos foi realizado de maneira remota.

Uma das principais ações do projeto foi direcionar esforços para elaborar e executar um curso de extensão com carga horária de 30 horas, além de criar recursos pedagógicos e materiais informativos em forma de publicações para a página no Instagram, através do perfil virtual do Núcleo de Estudos em Gênero, Geração 
e Raça ( @ neggra.ufrrj). As atividades de extensão, propostas de maneira on-line, foram e ainda são um desafio, sobretudo, quando se trata de atividades com enfoque em terminologias como gênero, feminismos, transversalidade, uma vez que no âmbito do senso comum são difundidas de maneira equivocada e com pouca reflexão crítica.

A seguir, apresentam-se os objetivos que orientaram as ações do projeto, bem como a metodologia empregada e os resultados alcançados.

\section{OBJETIVOS}

O objetivo geral do projeto de extensão em Direitos Humanos se resumiu em ampliar conhecimentos e competências acerca do conceito e da aplicabilidade da transversalidade de gênero no campo das Políticas Sociais em Seropédica-RJ. E como objetivos específicos, buscou-se despertar o pensamento crítico e reflexivo acerca dos estereótipos, desigualdades e violência de gênero; Debater sobre os elementos e conceitos que perpassam a transversalidade de gênero e sua aplicação nas políticas sociais, articulando-os à perspectiva dos direitos humanos e aos direitos das mulheres; E compreender o agravamento das demandas das mulheres no período da pandemia do novo Coronavírus e a urgência em se pensar políticas sociais que possuam a transversalidade de gênero. Ademais, havia no projeto as metas específicas: Promoção de esclarecimento e reflexão dos participantes, através do estreitamento das relações acadêmicas entre universidade e comunidade local; Visibilidade das ações do projeto pela comunidade acadêmica da UFRRJ; Realização de parcerias futuras para novos projetos de extensão (e pesquisa), e, havia, também, um planejamento das atividades caso as aulas presenciais retornassem.

Neste artigo, objetiva-se, portanto, apresentar os resultados alcançados com as ações do referido projeto, bem como refletir sobre a interface entre a extensão universitária, a transversalidade de gênero e as políticas sociais como ferramentas importantes para o alcance de uma maior equidade social.

\section{METODOLOGIA}

Realizar ações no campo da extensão universitária é um compromisso que as instituições de Educação Superior possuem com a sociedade para terem acesso aos resultados de uma troca horizontal de saberes, aprendizagem e ciência, de acordo com o tripé universitário de ensino-pesquisa-extensão e para traduzir o ensino acadêmico para o acesso de todos (as). A extensão permite integrar a Universidade com as demandas da população, agindo em uma via de mão dupla, ao, também, apreender algumas questões da própria comunidade.

No projeto em questão procurou-se discutir a perspectiva dos direitos humanos e a transversalidade de gênero, dois conceitos que precisam ser ampliados e desmitificados no imaginário social, levando em consideração a atual conjuntura política que profere ataques contra essas temáticas com informações falsas. Sendo assim, a 
primeira ação foi planejar e executar um curso de extensão, com carga horária de 30 horas, que promoveu um espaço dialógico e reflexivo junto aos participantes.

Considerando que a pandemia do novo Coronavírus alterou as dinâmicas sociais e de trabalho, modificou também o espaço de diálogo para a possibilidade de uso da internet, principalmente por meio das redes sociais (UEMA, 2020; SCHEIDEMANTEL; KLEIN; TEIXEIRA, 2004). E, assim, com a necessidade de distanciamento social, as atividades foram realizadas remotamente nas plataformas digitais Jitsi Meet e RNP. Dessa forma, percebemos uma nova possibilidade com o uso do ambiente virtual e elaboramos estratégias para manter o interesse do público-alvo do curso e continuar mantendo um certo vínculo de aproximação.

A finalidade do mencionado curso de extensão era de que os participantes compreendessem o conceito de transversalidade de gênero e sua importância nas Políticas Sociais, trazendo o recorte do contexto pandêmico. A fase de planejamento consistiu em reuniões semanais, levantamento de dados em artigos científicos e publicações do material informativo nas redes sociais. Além disso, foram listados alguns vídeos, que eram exibidos em paralelo às aulas expositivas. Na prática extensionista aqui descrita, os sujeitos participantes eram instigados e provocados para a leitura e demonstração de inquietações, o que reforçava a intenção de que o conteúdo ministrado na "sala de aula virtual" não se esgotava ali, naquele espaço.

Foram utilizados questionários semiestruturados na plataforma Google Forms para a avaliação do curso com os/as participantes, com o objetivo de visualizar quais foram os pontos fortes e fracos da ação. A esse tipo de avaliação participativa é conferida a dimensão de um processo pedagógico, considerando que o público-alvo tem uma maior clareza de suas necessidades e, assim, fazer a exposição delas por meio desse instrumento. Assim, as informações são repassadas à equipe executora e, nessa dinâmica, os atores adquirem o aprendizado mútuo, tendo em vista a ausência de hierarquia de saberes, como salienta Barbosa (2001).

Conforme mencionado anteriormente, as redes sociais virtuais tem sido a principal porta de comunicação no contexto da pandemia. Segundo estudo divulgado pela consultoria Kantar (2020), durante esse período o uso do Instagram, Whatsapp e Facebook aumentou mundialmente em 40\%, pela amostragem de 25.000 usuários. Considerando o potencial das mídias digitais, após o encerramento do curso, as atividades do projeto foram realizadas utilizando como principal canal de comunicação, o perfil do NEGGRA na rede social virtual Instagram. Os efeitos dessas comunidades virtuais podem ser refletidos fora desse contexto, tendo interação com o Estado, sociedade civil, movimentos sociais e outras instituições (MARTELETO, 2001 apud OLIVEIRA, 2017).

O perfil virtual do NEGGRA foi um espaço utilizado para a divulgação do material informativo elaborado, tais como: cards, divulgação de eventos, vídeos e lives acerca de temáticas que perpassavam a categoria gênero. O público-alvo do perfil do núcleo é composto por alunas/os da UFRRJ, discentes do curso de Serviço Social e por pessoas da comunidade externa.

A partir das publicações, foi possível perceber como a interação dos seguidores da página com os temas propostos se dava de forma mais dinâmica, através de likes (curtidas), comentários e compartilhamentos, 
corroborando com a análise de Silva (2020), que afirmou que, com a tecnologia em mãos, o conhecimento pode chegar de uma forma mais acessível e rápida, promovendo o desenvolvimento humano e social nesse novo modo de operar a extensão universitária.

Ressalta-se que, para além do curso de extensão e do conteúdo elaborado e divulgado no Instagram, foi elaborada uma cartilha com o título "Políticas Públicas para as Mulheres", com temas diversos sobre os direitos sociais desse grupo, inclusive, compreendendo as diferentes demandas, a partir do conceito da 'Interseccionalidade'ii.

\section{RESULTADOS E DISCUSSÃO}

Em uma primeira análise, serão destacados, a seguir, os temas desenvolvidos no curso de extensão: O conceito de gênero e transversalidade de gênero; Gênero e Direitos Humanos; Políticas Sociais no Brasil e a transversalidade de gênero; Feminismos; Políticas de gênero ou políticas para as mulheres?; A vida das mulheres na pandemia.

Além das aulas expositivas apresentando os temas, foram divulgados os resultados de uma pesquisaação realizada em Seropédica, com as ações que antecederam o projeto de extensão no ano de 2019, explicitado neste artigo. Ao longo do curso, era intenção da equipe executora percorrer um caminho coerente na explanação dos temas, começando pela apresentação de um conteúdo geral e, com o passar do tempo, ministrando aulas mais específicas dentro da aplicabilidade da transversalidade de gênero.

No período de inscrições, foram abertas 20 vagas, das quais 19 foram ocupadas e, por essa atividade ter sido realizada remotamente, foi possível abarcar como público-alvo das ações estudantes e profissionais do Nordeste, região Sul Fluminense e Baixada Fluminense, de São Paulo e outras localidades da região metropolitana do Rio de Janeiro. Além disso, os participantes eram profissionais de diferentes áreas, como História, Serviço Social, Ciências Sociais, Psicologia, Gestão Pública, etc. Em se tratando do perfil, o público era majoritariamente feminino, com apenas quatros homens, onde se supõe que ainda prevalece um interesse maior, no que tange às questões de gênero, entre as mulheres.

A partir da intenção de transferir conhecimento e informações aos participantes de uma maneira clara, foram feitas indicações de vídeos curtos para análise crítica, como sugestão de atividade assíncrona, para debates nos encontros síncronos seguintes. Um dos vídeos indicados foi o da série "Fala Direito Comigo: O que é isso, gênero?", do canal Clínica de Direitos Humanos da UFPR.

Ademais, foi solicitada a leitura do principal documento nacional e que introduziu a temática da transversalidade de gênero: "Brasil: Fortalecimento da Secretaria Especial de Políticas para as Mulheres - para avançar na transversalização da perspectiva de gênero nas políticas públicas”, elaborado pela cientista social Lourdes Bandeira, reforçando, assim, um compromisso do Estado em reduzir as desigualdades de gênero e o fortalecimento da autonomia política e econômica das mulheres, encontrando vias para a profissionalização e o 
incentivo à educação. Ressalta-se, no entanto, que ainda é necessário pensar sobre a vida das mulheres no contexto da pandemia, haja vista que, segundo pesquisa divulgada pela ONU Mulheres (2021), 54 milhões de mulheres perderam seus empregos.

Percebeu-se, com a sequência das aulas e, através das sugestões de vídeos e da leitura crítica de textos, que as/os alunas/os eram estimuladas/os a expor suas opiniões, questionamentos e vivências, demonstrando que se identificavam com o conteúdo desenvolvido. Além disso, foi proporcionado um canal de diálogo horizontal, enfatizando que o processo de aprendizagem acontecia para as ambas as partes: para a equipe executora e para o público-alvo das ações, destacando o caráter dialógico e participativo das ações propostas. No início dos encontros síncronos, havia sempre algumas/os alunas/os mais participativas/os e dispostas/os a interagir e debater sobre os temas.

Uma das inquietações demonstradas por parte do público-alvo era de que o conceito de transversalidade de gênero poderia ser excludente, inclusive, uma aluna não se sentia contemplada com uma das referências bibliográficas utilizadas. Elucidando uma falta na perspectiva racial e da diversidade sexual, a cursista questionava onde estariam as demandas das mulheres trans, por exemplo. Essa fala também provocou a equipe executora a buscar artigos que discutissem sobre o tema da transexualidade e transversalidade de gênero, porém, constatou-se que há poucas produções científicas nesse contexto. Na verdade, esse termo ainda é pouco difundido na esfera acadêmica e pública, não recebendo a atenção que merece (ANDRADE; MEYER; BARZOTTO, 2019).

Ainda sobre o curso de extensão realizado no âmbito do projeto, foi elaborado um questionário semiestruturado com algumas questões de cunho avaliativo das ações, material disponibilizado e metodologia. Também foi proposta uma questão de autoavaliação, em que o público poderia refletir sobre a sua participação nas atividades síncronas e assíncronas. Por fim, foi disponibilizado um espaço para sugestões, elogios e críticas.

O resultado das perguntas foi bastante positivo, onde o público-alvo externou uma relativa satisfação sobre as ações propostas pela equipe executora, o que trouxe a sensação de "dever cumprido". Foram recebidos um total de 12 (doze) feedbacks a respeito do curso, o que se considera um ponto negativo, tendo em vista que sete pessoas não frequentaram o curso e/ou só apareceram em uma única aula.

Todas/os as/os participantes relataram que o curso atendeu as expectativas, por ter apresentado um aprofundamento nas temáticas propostas e que o conteúdo foi esclarecedor e acessível a partir de um espaço de trocas.

Ao serem questionados se participariam de uma próxima edição do curso, apenas uma pessoa, entre as/ os alunas/os, respondeu 'talvez' e o restante respondeu sim, possivelmente, por ser uma discussão que não se esgota e pode ter diversos desdobramentos. Os participantes responderam que gostaram da dinâmica e da metodologia apresentada, ressaltando a necessidade de englobar, de forma mais ampla, a categoria raça/etnia. Como sugestão, foi proposto pensar as questões de gênero pelo viés da masculinidade, tendo em vista os papéis ideais de gênero que (também) são atribuídos aos homens. 
No que se refere as ações no perfil do Instagram do NEGGRA, a primeira atividade, no dia 24 de fevereiro de 2021, foi uma colaboração com o projeto de extensão “Construindo pontes e ressignificando saberes a partir das questões de gênero e raça/etnia: Atividades de extensão no campo da Assistência Social em Paracambi-RJ”, que teve como resultado a elaboração de conteúdo audiovisual sobre o conceito de gênero, com os títulos “O que é a violência de gênero" e "Tipos de violência contra a mulher".

O primeiro vídeo teve um alcance 160 (cento e sessenta) visualizações e seis comentários, e o segundo vídeo 71 (setenta e uma) visualizações. A partir do desempenho das publicações dos vídeos, acreditamos que ter separado o tema não foi uma boa estratégia pelo baixo número de views (visualizações). A finalidade da referida publicação com os vídeos foi compartilhar a informação sobre os principais canais de denúncia de violência contra a mulher e informar que o único culpado é o agressor. Essa temática merece destaque a partir dos dados que evidenciam que a violência doméstica aumentou durante o período pandêmico, conforme aqueles divulgados pela plataforma Ponte Jornalismo, onde se constatou que a violência contra a mulher no país acresceu em 5\%, quando se compara ao mesmo período de março e abril de 2019, além de o número de feminicídios, que saltou de 186 para 195 mortes (PONTE, 2020).

Dando seguimento, considera-se importante enfatizar a mudança de um ciclo para início de outro, elucidando que o projeto se tratou de uma continuidade de uma pesquisa anterior, inaugurando o novo quadro "Diálogos sobre gênero por meio da extensão universitária", espaço em que a bolsista trouxe discussões que transversalizam a categoria gênero.

O vídeo seguinte discutiu o tema da diferença entre políticas de gênero e políticas para as mulheres, considerando que, ainda no senso comum, a categoria gênero é vista como sinônimo de mulheres e que as ações estatais nela centralizadas, estão pautadas na redução da desigualdade socioeconômica e política das mulheres, no fortalecimento da autonomia financeira da mulher e na não reprodução de estereótipos de gênero nas políticas sociais. Esse conteúdo, em específico, alcançou 101 (cento e uma) visualizações.

O último vídeo foi uma colaboração com outro projeto de extensão intitulado "Violência contra o Idoso nos municípios de Seropédica, Japeri e Itaguaí: Mapeamento das denúncias nas ações de enfrentamento e garantia dos direitos humanos". Nessa atividade, abordou-se a relação entre a expectativa de vida ao recorte de raça e gênero, em cidades da região metropolitana do Rio de Janeiro. Além disso, explorou-se o significado da "feminização da velhice", deixando claro que o envelhecimento não é o mesmo para todos os sujeitos.

Outras ações foram articuladas ao projeto, como a elaboração de cards com um teor didático e uma linguagem clara para não haver barreira de comunicação com o público, apresentando temas diversos acerca de gênero e políticas sociais.

As discussões virtuais evidenciadas posteriormente foram a respeito da origem do dia 08 de março (Dia Internacional da Mulher), com a finalidade de politizar essa data, demonstrando que não é só um período onde as mulheres são homenageadas e sim, um dia para a conscientização por uma maior equidade de gênero. Essa foi 
uma das postagens mais acessadas com cinquenta e sete likes. A partir disso, percebeu-se que, quando são abordados assuntos em evidência no momento, há um maior número de compartilhamentos e engajamento na própria rede social.

Inaugurou-se no mesmo perfil digital o quadro "Histórias de mulheres que a história não conta", trazendo figuras femininas negligencias no conteúdo pedagógico, como por exemplo, Laudelina de Campos Melo, trabalhadora doméstica, que reivindicou a regulamentação dessa profissão e também lutava pelos direitos sociais das pessoas pretas.

Também foi criado o quadro "Dicio NEGGRA" com a finalidade de compreender autores/as e conceitos trabalhados pelo núcleo, para que o público-alvo ampliasse seus conhecimentos. A título de exemplo, foram explicitados os termos sobre Racismo Recreativo e Violência Simbólica. Além disso, explicou-se o que é o Plano Nacional de Atenção Integral à Saúde da Mulher, documento importante que discute as especificidades das mulheres, onde, em específico, foi abordado o tema da saúde da mulher lésbica, destacando os aspectos heteronormativos da sociedade que invisibilizam esse grupo.

No âmbito dos direitos femininos, foram dispostas informações acerca do que são os direitos reprodutivos e sexuais. Como o NEGGRA inclui em suas ações a discussão da categoria geração e é sabido que mulheres idosas são duplamente desvalorizadas, foram trazidos como temas os "Tipos de violência contra os idosos(as)" e o conceito da "Feminização da Velhice", evidenciando que as mulheres envelhecem mais do que os homens, mas que não envelhecem com qualidade, em função das desigualdades de gênero, com destaque para a desproteção social e econômica ao longo de suas vidas.

Compreendendo as particularidades das mulheres, é importante não unificar as demandas. Dessa forma, foram elaboradas duas publicações sobre a "Mulher indígena" e "Os direitos sociais dos indígenas", explicando o direito à terra e à diferença, e de que forma opera o movimento das mulheres indígenas e informando sobre a violência contra a mulher indígena e a saúde dos grupos originários. Com essa atividade se reforça a importância em se debater o assunto, uma vez que os conflitos do campo foram recordistas na pandemia. De acordo com o Relatório anual da Comissão Pastoral da Terra, das 81.225 vítimas de invasões, 58.327 foram de famílias indígenas, o que representa 71,8\% do total. No ano de 2019 os números apontavam para 26.621, em torno de 66,5\% das famílias indígenas (PROJETO COLABORA, 2021). De acordo com o recorte racial, explorou-se o conceito de racismo ambiental que é afastado pela mídia, onde indígenas e negros periféricos sofrem com danos ambientais.

No mês de junho comemora-se o "Mês de Orgulho LGBTQIA+", logo, concluiu-se sobre a relevância em apresentar a origem da data com seu significado político. Além disso, reforçou-se na mesma rede social, a diferença de opção e orientação sexual, destacando que o primeiro termo não se usa. Por fim, foi pontuada a diferença entre sexo, gênero e sexualidade, porque no senso comum, ainda, há uma confusão entre essas nomenclaturas. 
Na tentativa de interagir mais com o público-alvo, utilizamos os mecanismos da caixa de perguntas e enquetes do Instagram. Em relação à primeira opção houve um baixo engajamento, às vezes, sem resposta alguma. No entanto, as pessoas demonstravam uma maior participação ao ‘clicarem’ nas enquetes quando eram questionadas se conheciam o tema discutido na semana. Cabe ressaltar que a maioria das imagens publicadas no Instagram possuía a hashtag “\#pracegover”, com a finalidade de a informação ser acessível para todos(as). Além disso, o conteúdo apresentado continha as referências bibliográficas na descrição. A seguir, apresentamos alguns exemplos de cards elaborados ao longo do projeto:

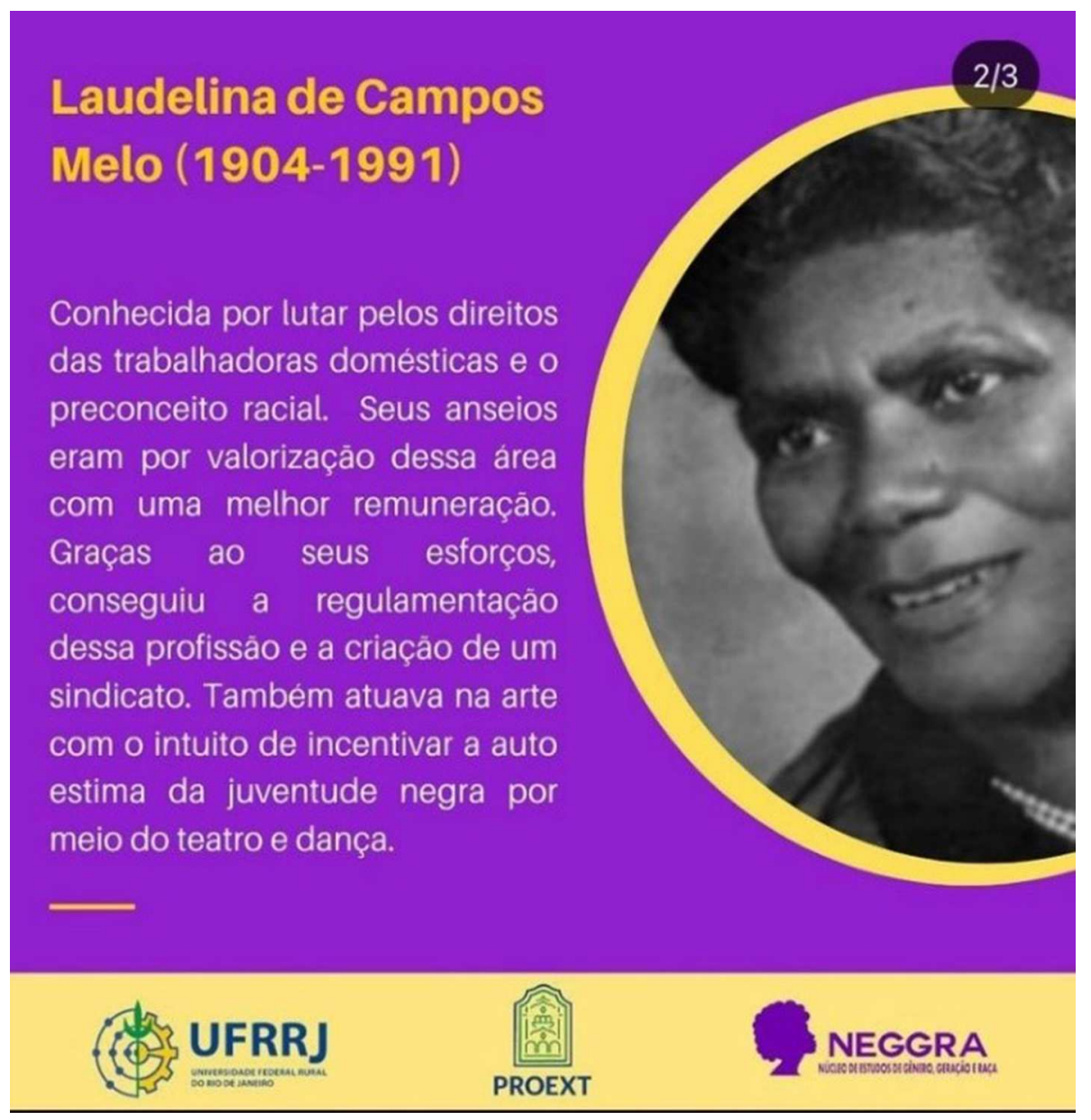

Figura 01 - Quadro "História de mulheres que a história não conta".

Fonte: Instagram@neggra.ufrrj

O card em questão teve como objetivo atrair a atenção da audiência da rede social virtual Instagram, destacando como as mulheres são invisibilizadas, sobretudo as mulheres negras, em conteúdos da disciplina de História nas escolas. Por meio de um recorte histórico, o leitor pôde visualizar a importância da luta e resistência da ativista por direitos das trabalhadoras domésticas, Laudelina de Campos Melo. Com a publicação do card a intenção foi provocar os sujeitos a buscarem mais informações acerca dessa história, que não é publicizada em nossa sociedade machista, heteronormativa, racista e patriarcal. 


\section{Saúde da mulher lésbica}

As mulheres lésbicas devem ser

contempladas nas ações que se referem

a saúde da mulher. A agenda de

necessidades desse grupo populacional

diz respeito, dentre outras, ao

atendimento na área da ginecologia, em

que os profissionais partem do

pressuposto de que a vida sexual ativa é

sempre de caráter heterossexual. Os

textos e ações sobre violência contra a

mulher não abordam as especificidades

das mulheres lésbicas. Não se pode

desconsiderar a violência intrafamiliar

contra adolescentes lésbicas quando são

expulsas do lar.

Figura 02 - Informativo sobre o Plano Nacional de Atenção Integral à Saúde da Mulher Fonte: Instagram@neggra.ufrrj

A intenção da publicação na rede social virtual Instagram foi desmitificar o fato de as demandas das mulheres serem unificadas, destacando a saúde das mulheres lésbicas. O referido grupo sofre uma dupla opressão, pela condição de ser mulher e LGBTQIA+, num país com grande número de feminicídios e lesbofobia. A vida sexual das mulheres não deve ser considerada por apenas um viés, levando-se em consideração, também, a conscientização do uso de preservativos, por exemplo. Também se provocou a discussão sobre a violência intrafamiliar, mesmo havendo casas de acolhimento LGBTQIA+, uma vez que mesmo através de ações de organizações não governamentais, a demanda não é atendida em sua totalidade pela baixa cobertura.

Em maio de 2021 a estudante extensionista colaborou na organização da palestra oferecida pelo NEGGRA, com o tema "Políticas Sociais de Gênero: Desafios e possibilidades", ministrada por uma docente do Departamento de Serviço Social da PUC- RJ. Na referida atividade foi possível dialogar com os resultados do estudo em Seropédica e as ações de extensão propostas posteriormente. A bolsista teve, ainda, a oportunidade de participar como ‘colaboradora' no projeto “Violência contra o Idoso nos municípios de Seropédica, Japeri e Itaguaí: Mapeamento das denúncias nas ações de enfrentamento e garantia dos direitos humanos" em dois eventos, dialogando sobre recorte de gênero, raça e sexualidade na perspectiva do envelhecimento.

Conforme mencionado na metodologia, como atividade final do projeto, foi elaborada uma cartilha sobre as políticas públicas para as mulheres, na qual foram destacadas as principais legislações e direitos das mulheres. 
Reitera-se que as mulheres possuem demandas específicas, assim sendo, foi enfatizado o conceito de interseccionalidade e os direitos sociais e políticos acerca da mulher lésbica, indígena, negra, em situação de prisão e transexual.

Vale mencionar que as especificidades femininas não se limitam a esses segmentos, e acredita-se que a cartilha é uma ferramenta inicial para o aprofundamento teórico da temática proposta. O público que se pretendeu atingir é a equipe técnica dos espaços da Assistência Social em Seropédica, os discentes do curso de Serviço Social e o público do perfil do NEGGRA no Instagram. A seguir, ilustramos com a capa da cartilha que foi desenvolvida pela extensionista e outros integrantes do núcleo:

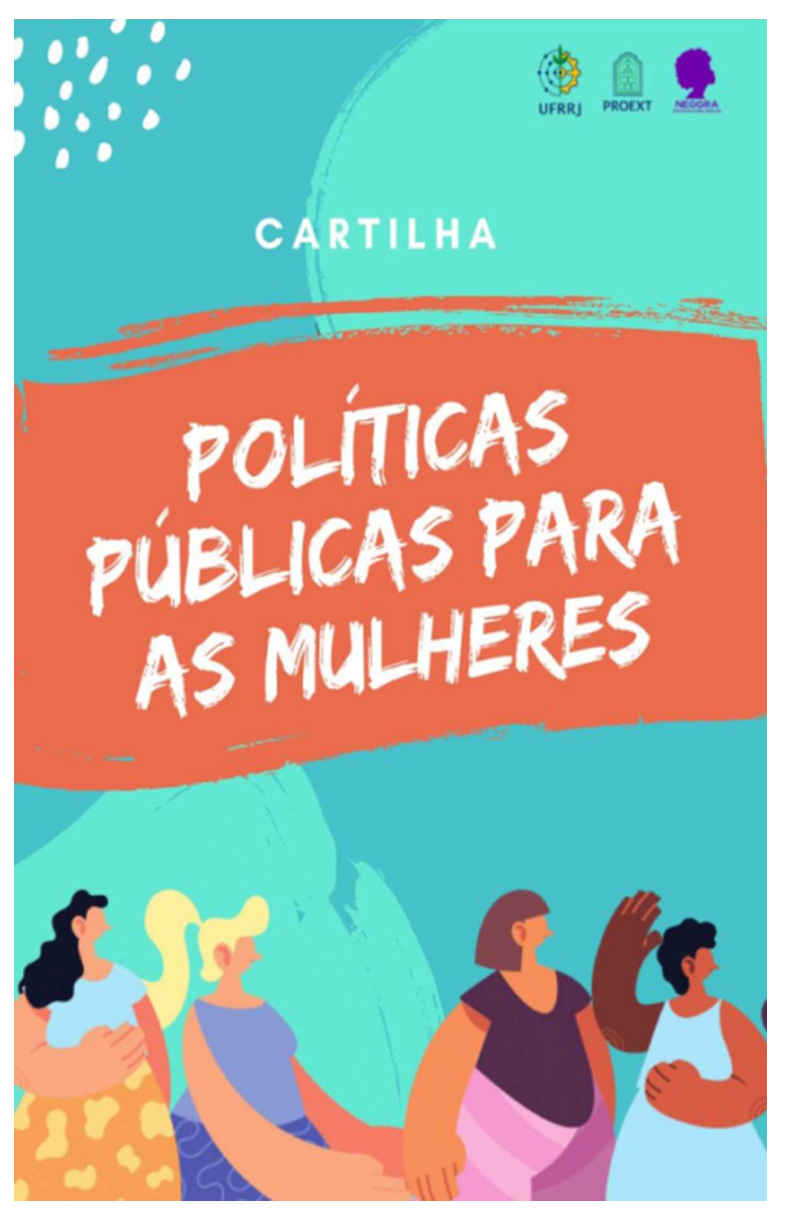

Figura 03 - Material elaborado na plataforma de edição de imagens Canva.

Fonte: Arquivo pessoal.

A imagem em questão é a capa da cartilha que trouxe em seu bojo a discussão sobre alguns exemplos de políticas públicas para as mulheres. Na referida capa, utilizou-se o desenho de mulheres de diferentes etnias para destacar a importância da diversidade e que cada grupo possui suas particularidades e demandas. Em todo o documento, é tratado o conceito de interseccionalidade, além de problematizar que, mesmo com os avanços de políticas para esse público, há constantes ataques e sucateamentos em termos de recursos e efetivação de direitos. 
A discussão sobre as mulheres negras, na mesma cartilha, reforça a ideia de que esse grupo está inserido em uma parcela mais empobrecida da sociedade e, comparando-se aos salários, recebem menos que as mulheres brancas. A mulher negra com renda mensal de até $\mathrm{R} \$ 285,00$ simboliza o perfil do Cadastro Único (GELEDES, 2020). O CadÚnico, como é popularmente chamado, é um cadastro para famílias de baixa renda para ter acesso aos benefícios sociais. Dessa forma, é necessário pontuar políticas de geração de renda para mulheres, além do incentivo à educação.

\section{CONCLUSÕES}

A partir da discussão apresentada neste artigo, corrobora-se a importância do fortalecimento do tripé ensino-pesquisa-extensão para se democratizar a informação produzida no interior da universidade pública de forma clara, rompendo barreiras e oportunizando o acesso à informação a pessoas que não estão inseridas no meio acadêmico.

A finalidade da extensão é trazer impactos positivos, tanto para a comunidade interna da UFRRJ, como para a comunidade externa e a universidade não deve estar afastada da sociedade como um todo, deve principalmente entender as demandas do grupo localizado em seu entorno. Temáticas que envolvem as categorias gênero e raça ainda possuem um distanciamento do senso comum, sobretudo em um contexto conservador resultante da atual conjuntura política, que dissemina muitas inverdades, por meio de fakes news, envolvendo o ensino público e sobre as categorias que foram colocadas em pauta, no projeto aqui apresentado. Diante disso, consideramos a relevância de compreendê-las de maneira crítica e reflexiva, para firmar o compromisso social contra as desigualdades e opressões de classe, gênero, geração e raça/etnia.

Destaca-se, ainda, que foi um constante desafio executar um projeto de extensão de forma remota, diante das variáveis como, instabilidade da internet e a criação de habilidades em programas de edição de vídeos e mídias digitais. No entanto, com os resultados obtidos, a equipe executora considera que as ações foram exitosas, ao trazer o conceito da transversalidade de gênero, tão pouco discutido na esfera acadêmica e decodificado para a sociedade. A principal intenção com essa publicação é que esse conceito se amplie cada vez mais para o cotidiano.

Enfim, concluímos que os temas abordados pelo projeto não se esgotam e, mesmo com o desenvolvimento do curso de extensão e o material pedagógico em forma de cards, palestras e conteúdos audiovisuais, ainda é preciso bastante articulação e discussão acerca de gênero e as demais categorias que o circundam.

\section{AGRADECIMENTOS}

Agradecemos à PROEXT e a Universidade Federal Rural do Rio de Janeiro (UFRRJ) pela concessão das bolsas de extensão do Programa Direitos Humanos 2020, no âmbito do Edital nº 26/2020, às/aos inscritos/ 
os do curso pela disponibilidade em participar das atividades propostas e à audiência dos seguidores do perfil do NEGGRA no Instagram.

\section{NOTAS}

${ }^{\mathrm{i}} \mathrm{O}$ referido projeto se deu em continuidade a um projeto de pesquisa anterior, intitulado "A transversalidade de gênero nas Políticas Sociais: Mapeando ações no munícipio de Seropédica - RJ”, que teve como objetivo compreender de que maneira era operacionalizada a categoria gênero em dois equipamentos da política de Assistência Social - o Centro de Referência de Assistência Social (CRAS) e um espaço especializado em atendimento às vítimas de violência doméstica.

ii Empregando uma metáfora de "intersecção", Crenshaw (2002) relaciona os vários eixos de poder, como raça, etnia, gênero e classe como se formassem avenidas que organizam os terrenos sociais, econômicos e políticos. Nos termos da autora, através dessas "avenidas" as dinâmicas do desempoderamento se movem. Essas vias, então, são verificadas como "eixos de poder distintos e mutuamente excludentes": o racismo, por exemplo, não é igual ao patriarcalismo que, por sua vez, é diferente da opressão de classe. Crenshaw (2002) elucida que tais sistemas, frequentemente, se sobrepõem e se cruzam, apontando intersecções complexas onde dois, três ou quatro eixos se entrecruzam.

\section{REFERÊNCIAS}

ANDRADE, Sandra dos Santos; MEYER, Dagmar Elisabeth Estermann; BARZOTTO, Carlos Eduardo.Transversalidade de gênero em políticas públicas: Uma revisão de literatura. Revista Práxis, Novo Hamburgo, n 2, p 82-106, mai/ago, 2019.

BARBOSA, Ricardo Machado. Monitoramento e avaliação de projetos sociais. Trabalho de Conclusão do Programa de Pós-Graduação em Desenvolvimento Rural. Especialização em Desenvolvimento Rural e Agroecologia. Universidade Federal do Rio Grande do Sul. Porto Alegre. 2001.

BRASIL. Denúncias registradas pelo Ligue 180 aumentam nos quatro primeiros meses de 2020. Ministério da Mulher, da Família e Direitos Humanos. 2020. Disponível em https://www.gov.br/mdh/pt-br/assuntos/noticias/ 2020-2/maio/denuncias-registradas-pelo-ligue-180-aumentam-nos-quatro-primeiros-meses-de-2020. Acesso em: 26 out. 2021.

CRENSHAW, Kimberlé. Documento para o encontro de especialistas em aspectos da discriminação racial relativos ao gênero. Revista Estudos feministas, p.171-189, 2002.

IBGE. Estatísticas de Gênero - Indicadores sociais das mulheres no Brasil, 2018. Disponível em: https:// www.ibge.gov.br/estatistic\%20as/multidominio/genero/20163-estatisticas-de-genero-indicadoressociais-dasmulheres-nobrasil.html . Acesso em: 26 out. 2021.

NAÇÕES UNIDAS BRASIL. ONU Mulheres defende que recuperação econômica e igualdade de gênero estão associados. 2021. Disponível em: https://brasil.un.org/pt-br/144883-onu-mulheres-defende-querecuperacao-economica-e-igualdade-de-genero-estao-associados. Acesso em: 28 set. 2021.

OLIVEIRA, Carlos Alexandre; ANGELO, Edna Silva; OLIVEIRA, Marlene. Análise de redes sociais no campo de pesquisa da Ciência da Informação: Desenvolvimento da produção científica mundial. Revista ACB: Biblioteconomia em Santa Catarina, Florianópolis, v. 22, n. 2, ESPECIAL, p. 312-328, abr./ jul., 2017. 
PONTE JORNALISMO. Um vírus e duas guerras: mulheres enfrentam em casa a violência doméstica e a pandemia da Covid-19. Disponível em: https://ponte.org/mulheres-enfrentam-em-casa-a-violencia-domesticae-a-pandemia-da-covid-19/ . Acesso em: 30 set. 2021.

PORTAL GELEDES. Mulher negra com renda mensal de $\mathrm{R} \$ 285$ é perfil de maioria no Cadastro Único. 2020. Disponível em https://www.geledes.org.br/mulher-negra-com-renda-mensal-de-r-285-e-perfil-demaioria-no-cadastro-unico. Acesso em 16 nov. 2021.

PROJETO COLABORA. Conflitos no campo batem recorde no ano da pandemia. 2021. Disponível em https://projetocolabora.com.br/ods16/conflitos-no-campo-batem-recorde-no-ano-da-pandemia/. Acesso em: 01 out. 2021.

SCHEIDEMANTEL, Sheila Elisa; KLEIN, Ralf; TEIXEIRA, Lúcia Inês. A Importância da Extensão Universitária: o Projeto Construir. Anais do $2^{\circ}$ Congresso Brasileiro de Extensão Universitária Belo Horizonte, Universidade Federal de Minas Gerais (UFMG), 2004.

SILVA, Márcia Costa Alves; MELLO, Leonardo José A; CAMPELLO, Luciana; ARRUDA, Maria Clara; NEVES, Paula Carvalho. Democracia e gênero [livro eletrônico]: implantação de políticas públicas para mulheres. Rio de Janeiro: IBAM, SPM, 2015.

UNIVERSIDADE ESTADUAL DO MARANHÃO. A Extensão Universitária no Cenário Atual da Pandemia do COVID-19. 2020. Disponível em https: www.uema.br/2020/07/artigo-a-extensao-universitaria-nocenario-atual-dapandemia-do-covid-19/. Acesso: em 17 ago. 2021.

Submetido em: 19/10/2021 Aceito em: 23/11/2021. 